\title{
Evidence of the inaccuracy of standard echocardiographic and angiographic criteria used for the recognition of true and "false" left ventricular inferior aneurysms
}

\author{
G LASCAULT, F REEVES, G DROBINSKI \\ From the Service de Cardiologie, Hôpital de la Salpêtrière, Paris, France
}

SUMMARY Diagnosis of so-called false aneurysms of the left ventricle after infarction is judged to be important because the risk of rupture is high and resection of aneurysms with a narrow orifice is usually successful. Aneurysms with larger communication orifices are less likely to rupture. Echocardiographic and angiographic criteria have been devised to classify left ventricular aneurysms into two distinct types. In four cases of inferior aneurysms the echocardiographic and angiographic criteria were typical of a "false aneurysm" but the defects were diagnosed as true aneurysms after intraoperative and histological examination. These aneurysms were characterised by their site in the inferior wall and by late diagnosis and treatment, which may have influenced their occurrence and determined the development of their characteristic shape.

These findings suggest that the classic echocardiographic and angiographic diagnostic criteria for "false" aneurysms may have to be abandoned.

Left ventricular aneurysms with narrow communication orifices are more likely to rupture than aneurysms with wider necks. In 1975 Roelandt et al established echocardiographic criteria to differentiate between so-called false and true aneurysms. ${ }^{1}$ Angiographic ${ }^{2}$ and anatomical criteria ${ }^{3}$ have also been developed. The four patients we report had an inferior left ventricular aneurysm that developed after myocardial infarction; their echocardiographic and angiographic features were in every respect those that are regarded as being characteristic of a "false" aneurysm. At operation and histological examination, however, these so-called false aneurysms were found to be "true" aneurysms.

These findings suggest that the classic diagnostic criteria for "false" aneurysms may have to be abandoned, at least for inferior aneurysms.

Requests for reprints to Dr G Lascault, Service de Cardiologie (Pr Y Grosgogeat), Hôpital de la Salpêtrière, 47-83 Boulevard de l'Hôpital, 75013 Paris, France.

Accepted for publication 9 September 1987

\section{Case report}

All four patients had an acute myocardial infarction as the first sign of coronary artery disease. Diagnosis of myocardial infarction was delayed ( 12 hours to 2 months), mean 18 days after the onset of chest pain. This implied that there had been a long delay before bed rest and treatment were started (more than three days in three patients). The electrocardiogram indicated an inferior or inferolateral transmural infarction in all instances. All the patients had symptoms (congestive heart failure (two patients), angina pectoris (one patient), or palpitation related to ventricular extrasystoles (one patient)). Echocardiographic examination (Roche-Kontron RT 400 or Diasonics CV 4000) showed an inferior or inferolateral aneurysm in every patient between the mitral annulus and one of the papillary muscles, that was typical of a false aneurysm (fig). The following features were present: (a) evidence of a narrow orifice between the left ventricular chamber and the "aneurysm"; (b) at the end of systole the internal diameter of the orifice (O max) was much smaller than the maximal internal diameter (D max) of the aneurysmal sac and a ratio $O \max / \mathrm{D}$ max was much 


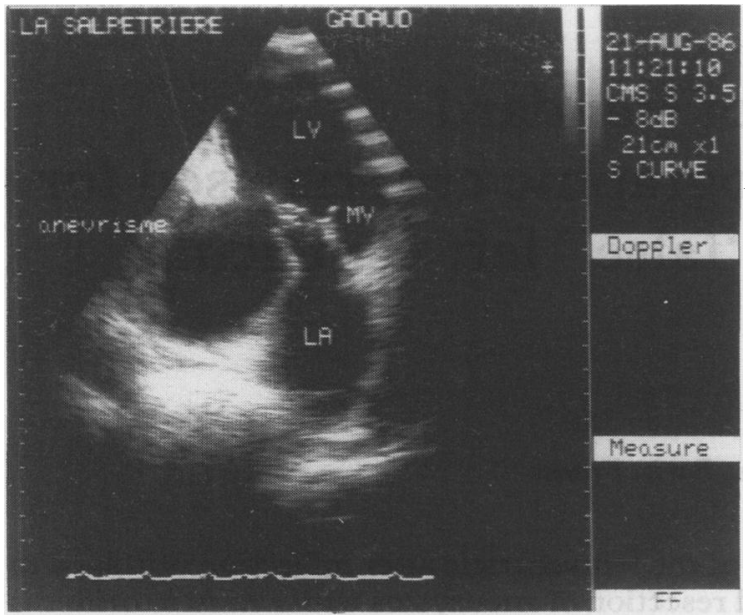

Figure An apical two chamber echocardiogram showing an aneurysm of the inferior left ventricle. $L V$, left ventricle; $L A$, left atrium; $M V$, mitral valve.

less than one; $(c)$ the "aneurysm" was saccular and there was an acute angle between the aneurysmal wall and the ventricular wall. ${ }^{46}$ The expansion of the aneurysmal formation in systole is not usually regarded as being specific. ${ }^{-6}$ The best echographic views for imaging the aneurysmal sac were the apical two chamber and subxiphoid four chamber. Left ventricular function was depressed in all the patients, with a fractional shortening of less than $26 \%(20-$ $26 \%$ ). The end diastolic diameter was also abnormal (60-70 mm). Angiographic data were consistent with the echocardiographic data and also suggested evidence of a false aneurysm ${ }^{47}$ (table). The table also shows other angiographic findings. The four patients were operated on because of their symptoms and because they were thought to have a false aneurysm.

Table Haemodynamic and angiographic data

\begin{tabular}{|c|c|c|c|c|}
\hline Data & $\begin{array}{l}\text { Patient } \\
1\end{array}$ & 2 & 3 & 4 \\
\hline $\begin{array}{l}\text { Site } \\
\text { EF } \\
\text { LVEDP }(\mathrm{mm} \mathrm{Hg} \mathrm{Hg}) \\
\operatorname{EDV}\left(\mathrm{ml} / \mathrm{m}^{2}\right) \\
\operatorname{ESV}\left(\mathrm{ml} / \mathrm{m}^{2}\right) \\
\text { An EDV }\left(\mathrm{ml}^{2} / \mathrm{m}^{2}\right) \\
\text { An ESV }\left(\mathrm{ml} / \mathrm{m}^{2}\right) \\
\text { O max } / \mathbf{D m a x} \\
\text { Coronary arteries } \\
\text { (\% stenosis) }\end{array}$ & $\begin{array}{l}\text { Inf } \\
0 \cdot 39 \\
16 \\
143 \\
87 \\
139 \\
151 \\
0 \cdot 38 \\
\text { Cx } 100 \%\end{array}$ & $\begin{array}{l}\text { Inf } \\
0 \cdot 25 \\
11 \\
148 \\
110 \\
8 \\
14 \\
0 \cdot 60 \\
\text { RCA } 100 \% \\
\text { LAD } 75 \%\end{array}$ & $\begin{array}{l}\text { Inf lat } \\
0 \cdot 37 \\
10 \\
91 \\
57 \\
31 \\
41 \\
0 \cdot 67 \\
\text { Cx } 100 \% \\
\text { RCA } 90 \%\end{array}$ & $\begin{array}{c}\text { Inf } \\
0 \cdot 28 \\
19 \\
283 \\
204 \\
104 \\
70 \\
0 \cdot 49 \\
\mathrm{Cx} 100 \%\end{array}$ \\
\hline
\end{tabular}

EF, ejection fraction; LVEDP, left ventricular end diastolic pressure; EDV, end diastolic volume; ESV, end systolic volume; An EDV, aneurysm end diastolic volume; An ESV, aneurysm end systolic volume; $\mathrm{Cx}$, circumflex artery; $\mathrm{RCA}$, right coronary artery; $\mathrm{LAD}$, left anterior descending artery.
But the intraoperative and histological findings were $\stackrel{T}{\Phi}$ typical of a true aneurysm according to several $\stackrel{2}{7}$ criteria. At operation a true aneurysm has a circums- $c$. cribed area of scar tissue which is thin and often $\vec{F}$ adherent to the pericardium. In this area elements of $\frac{(5)}{+}$ the original wall can be identified and the area may or may not bulge paradoxically in systole. ${ }^{49}$ Histologically a so-called true aneurysm is characterised $\stackrel{\frac{N}{\vec{T}}}{\vec{D}}$ by the presence of myocardial cells and coronary $\stackrel{\Phi}{\Omega}$ vessels in the aneurysmal wall. ${ }^{3}$

The aneurysms were resected in all four patients; one patient also had coronary artery bypass grafting. After at least one year of follow up all the patients were in New York Heart Association functional class I or II without angina.

\section{Discussion}

The diagnostic criteria for true and false aneurysms $\vec{N}$ have been developed and are now routinely used. ${ }^{146}$ 의 These criteria were derived from small series of $\rightarrow$ patients. ${ }^{146}$ None of these series had more than five $\gg$ patients with a false aneurysm. Diagnoses were usually based solely on echocardiography and क्? angiography because few patients had a surgical and $\overrightarrow{\vec{\theta}}$ histological examination. In our four patients the $\infty$ echocardiographic and angiographic findings were $\infty$ typical of a "false" aneurysm but true aneurysms were found at operation. Neither the width of the communication orifice, the ratio $\mathrm{O} \max / \mathrm{D} \max$, nor the angle between aneurysm wall and ventricular wall $\%$ could reliably distinguish between the two types. It is $\stackrel{\square}{\unrhd}$ possible that these criteria cannot be applied to $\overrightarrow{\vec{F}}$ lesions at inferior or inferolateral sites; these have not $\frac{\rho}{3}$ been extensively studied because they are so rare. Two features can be recognised as typical of inferior true aneurysms. Firstly, they occurred after late diagnosis therefore delaying initiation of bed rest and $\widetilde{\Phi}$ treatment. To our knowledge this potentially predisposing factor has not been identified previously. 웅 Secondly, an inferior infarction is located between two resistant structures-the mitral annulus and the $ᄋ$ papillary muscle-and if the wall stress is large enough an aneurysm may develop but its orifice willo necessarily be narrow.

In conclusion, the present study clearly shows that the present criteria that are used to differentiate between so-called true and false aneurysms should be reconsidered, particularly in the case of inferior or $N$ inferolateral aneurysms.

\section{References}

1 Roelandt J, Van der Brand M, Vletter WB, Nauta J, C Hugenholtz PG. Echographic diagnosis of pseudo- 
aneurysm of the left ventricle. Circulation 1975;52:466-72.

2 Visser CA, Kan G, David GK, Lie KI, Durrer K. Echographic-cineangiographic correlation in detecting left ventricular aneurysm: a prospective study of 422 patients. Am J Cardiol 1982;50:337-41.

3 Vlodaver Z, Coe JI, Edwards JE. True and false aneurysms. Propensity for the latter to rupture. Circulation 1975;51:567-72.

4 Gatewood RP, Nanda NC. Differentiation of left ventricular pseudoaneurysm from true aneurysm with two-dimensional echocardiography. Am J Cardiol 1980;46:869-78.

5 Catherwood E, Mintz GS, Kotler MN, Parry WR, Segal BL. Two-dimensional echographic recognition of left ventricular pseudo-aneurysm. Circulation
1980;62:294-303.

6 Katz RJ, Simpson A, Di Bianco R, Fletcher RD, Bates HR, Sauebrun BJL. Non-invasive diagnosis of left ventricular pseudoaneurysm. $A m \quad J$ Cardiol 1979;44:372-7.

7 Higgins CB, Lipton MJ, Johnson AD, Peterson KL, Vieweg VR. False aneurysms of the left ventricle: identification of distinctive clinical, radiographic and angiographic features. Radiology 1978;127:21-7.

8 Cohen M, Packer M, Gorlin R. Indications for left ventricular aneurysmectomy. Circulation 1983;67: 717-22.

9 Loop FD, Effler DB, Navia JA, Sheldon WC, Groves LK. Aneurysms of the left ventricle: survival and results of a ten-year surgical experience. Ann Surg 1973;126:523-8. 